\title{
Analysis on Training Mode of Marine Pharmacy Professionals in Marine Biomedicine
}

\author{
Wen Zhengshun ${ }^{\text {a }}$, Qu Youle \\ School of Food and Medicine \\ Zhejiang Ocean University \\ Zhoushan, Zhejiang 316022 \\ a zswenmr@163.com
}

\begin{abstract}
As an emerging industry, marine biopharmaceutics industry is the most energetic industry with the fastest growth. As the development of our country's marine economy enters a new phase, it is facing new development opportunities. The talents training of this industry should be improved and is of great significance. This paper researches on the talents training mode in marine pharmacy of marine biopharmaceutics and explores its innovative training mode, based on the integration of our school's marine pharmacy- the provincial new characteristic specialty talents training objective, method formulation and implementation.
\end{abstract}

Keywords—marine pharmacy, postgraduate, training mode

\section{INTRODUCTION}

Marine biopharmaceutics industry is the fastest-growing industry in 21 century. As one of the subjects with distinctive marine features, it is the zenith of technology in the marine organism resource research, development and utilization chain. As a result, it is urgent to raise the training level of marine biomedical innovative talents. As one of the seven strategic rising industry of our nation, marine biopharmaceutics industry(including marine medicine) boasts a huge potential for development and is in badly need of high quality, compound, innovative talents. Therefore, it is inevitable for ocean universities to cultivate talents engaging in ocean pharmaceutics industry. Located in Zhoushan Archipelago New Area-China's first national marine new area, Zhejiang Ocean University is the only ocean university in Zhejiang province. It features ocean, forms a cluster of professions with oceanic characteristics and enjoys the reputation of "the cradle of oceanic talents”. [1, 2]

\section{Marine Pharmacy specialty of ZheJiang Province}

Pharmacy profession was set in 2006 and has formed distinctive marine biopharmaceutics advantages and marine medicine characteristics through over 10 years' development. It is the special major in Zhejiang's university and colleges and the support of the marine biopharmaceutics courses in Zhejiang Province. We have established a master's degree in food processing and safe agricultural promotion and a master's degree in marine pharmacy. This major takes "demandoriented and ability" as the professional construction concept, and takes 'the combination of teaching and research, theory

Fund project: Zhejiang Education Reform Project "Reform and Innovation of Marine Pharmaceutical Talent Training Curriculum System and Teaching Content” (jg2015089) and practice, school-enterprise interaction and cooperation" as the school-running idea, and relies on provincial key disciplines, provincial specialty and innovative talents training experiment zone to serve the emerging marine biomedical industry in Zhejiang and Zhoushan Archipelago New Area. It also aims at training and applying innovative talents and grows as the first-class and domestically advanced specialty in the province. In the past ten years, it has trained nearly 1000 talents for pharmacy in Zhejiang Province and even the whole country This major adopts a new system of undergraduate education that is independent, individualized, practical, and researchfocused, and establishes a new model of "full-time tutor guidance, early participation in scientific research, and stratified and classified personnel training" [1, 3]. While receiving solid professional education, students can follow the tutors to participate in research and innovation activities such as pharmacological basic theory research, new drug research and development, collection and cultivation of marine organisms or medicinal plants, etc., according to their own qualities, abilities and hobbies. They can also choose to practice in the production technology management, quality management and clinical rational use of drugs in pharmaceutical companies, medical institutions and other offcampus practice bases. The profession has established longterm cooperative relationships with the United States, Italy, Japan, Singapore, Taiwan and other countries and regions, and the proportion of exchange students has increased year by year.

\section{TRAINING OBJECTIVES}

As one of the country's major strategic emerging industries, the marine biopharmaceutics industry entertains a huge potential to grow and is in badly need of high quality talents. In accordance with this characteristic, we set the purpose to cultivate application-oriented talents with consciousness of innovate, taking the marine pharmacy as characteristic, and serving this emerging industry as the objective. Students of this profession mainly learn the basic theory and knowledge of pharmacy and should master the experimental method and fundamental skills. The setting of this major is to produce skilled people with innovative ability to engage in marine pharmacy research, development, management, supervision and teaching. They should entertain the basic theory, knowledge and experimental skills. We are inclined to cultivate innovative talents that can engage in marine pharmacy research, development, production, management, supervision and 
teaching, and the advanced compound people possessing pharmaceutical theory, knowledge and experimental skills that can engage in medicine design, research, production, dose and quality control, clinical application and supervision and management. At the same time, to serve the marine economic development of Zhejiang province, Zhoushan Archipelago New Area, we also need to cultivate personnel that can take up medicine designing and synthesizing, pharmacological experiment and evaluation, quality standard customization and clinical rational drug use throughout the development of marine medicine.

\section{TALENT TRAINING MODE}

With the rapid development of our country's higher education, universities and colleges are besieged with problems such as the lack of learning motivation caused by professions' feature losing and mass education, and the practical and comprehensive application ability decreasing brought by diversified education.[4,5] This profession is set by the concept that facing the requirements and highlighting capability. This major has established a professional concept of "facing demand and highlighting ability". It is based on the idea of "focusing on teaching and research, combining theory and practice, and school-enterprise interaction and cooperation", and rely on provincial key disciplines, school key majors and innovative talents training experimental areas to serve the emerging marine biomedical industry in Zhejiang and Zhoushan Archipelago New Area. It sets the goal to cultivate innovative talents and achieve first-class and domestically advanced specialties in the province. Progress has been made in profession construction. We aim to cultivating students' theoretical knowledge, improving students' application skills and innovation ability, and cultivating innovative talents for the construction of emerging marine biomedical industry, based on which we have set the three-dimensional ability training mode, that is, "full-time tutor guidance, early participation in scientific research, advance according to different level of ability". We have also established the "platform + module + training" training program, formed a modular training model which consists of professional core curriculum module, professional direction elective course module, practice education module, etc. Combine professional theoretical knowledge with innovative practice and employment direction, integrate marine characteristics, focus on the cultivation of ability in the whole process of training, and develop a core capacity training plan. The professional core competence training system consists of basic abilities (basic chemical literacy, basic medical literacy, basic pharmacy knowledge), professional competence (drug preparation and use ability, marine drug research and development ability), application ability (drug management ability, new drug development ability, new drug design), innovation and entrepreneurial ability (pharmaceutical productivity, comprehensive ability), which have greatly promoted the cultivation of core competence of the pharmaceutical profession.

After nearly ten years of exploration and practice, we have gradually formed a talent training model of "one through" (the scientific research runs through the whole process), "two early" (students' early participation in scientific research, enterprises' early participation in training program formulation), "three processes" (The whole process of tutor system, quality control of the whole process, integration of theory and practice) and the 'three-in-one" curriculum system (industry development needs, enterprise capability requirements, innovation and entrepreneurship dual-capacity professional practice needs). We consistently adhere to the development of students, focus on the development of students' ability and personality, highlight the characteristics of the ocean, aim at serving the emerging industries of the strategy, and cultivate the comprehensive and application-orientation talents with innovative consciousness. As Zhejiang's marine economic development grows as the national strategy, the marine biomedical industry, the strategic emerging industry, is one of the key development industries of the National Ocean New Area, which has a great demand for marine pharmacy talents. As the only marine university in Zhejiang Province, Zhejiang Ocean University, located in the new marine area, has experienced rapid development of marine professions, especially the marine pharmacy profession. Through years of unremitting efforts and exploration, the university has trained more than 1000 marine biomedical (strategic emerging industries) talents that serve in Zhejiang marine economy, and Zhoushan Archipelago New Area.

\section{COURSE SETTING}

The main subjects of pharmacy major are Chemistry, Pharmacy and Biology; the core subjects are Medicinal Chemistry, Medicinal Chemistry of Natural Products, Pharmaceutics, Pharmacology, Pharmacoanalysis; the characteristic courses are Marine Pharmacy, Pharmaceutical Marketing, Innovative drug design seminar, Symposium for licensed pharmacists, Basic experiment skill training of pharmacy, and Comprehensive pharmaceutical design experiment. The practical teaching includes experimental courses, internship, practical training, social practice, innovation and entrepreneurship practice and graduation design.

In this major, there are two professional divisions for the cultivation of pharmacy talents. The marine medicine mainly focuses on cultivating students' research and innovative ability and basic skills in marine drug development. From the short semester of the first year, students will follow the tutor to enter the laboratory. Take part in relevant research work. The teaching content of innovation and entrepreneurship practice is mainly the basic research on the preparation, identification and biological activity of marine active substances. And the pharmaceutical marketing mainly focuses on cultivating students' ability to engage in corresponding pharmaceutical practice in the field of drug circulation and rational use. From the short semester of the first year, students will enter the hospital pharmacy department or large chain pharmacy to participate in practical activities. The practice teaching of innovation and entrepreneurship is mainly to get students familiar with the knowledge and skills of rational use of common drugs and drug marketing. 
TABLE I.

THE SPECIFIC COURSE GROUP MODULES

\begin{tabular}{|c|c|c|c|c|c|c|c|}
\hline Items & $\begin{array}{c}\text { Public basic } \\
\text { course }\end{array}$ & $\begin{array}{c}\text { General education } \\
\text { course }\end{array}$ & Basic course & $\begin{array}{c}\text { Core } \\
\text { course }\end{array}$ & $\begin{array}{c}\text { Practical } \\
\text { Professional course } \\
\text { and optional course }\end{array}$ & $\begin{array}{c}\text { teaching(Centralized } \\
\text { practical teaching } \\
\text { credits) }\end{array}$ & $\begin{array}{c}\text { Another course } \\
\text { Credit required }\end{array}$ \\
\hline $\begin{array}{c}\text { Percentage in } \\
\text { Total Credits(\%) }\end{array}$ & 21.8 & 12 & 30.5 & 22.5 & 36 & $49(28)$ & 4 \\
\hline
\end{tabular}

\section{PRACTICAL ABILITY TRAINING}

Pharmacy is a highly applied discipline with high requirements for practical ability. Therefore, the cultivation of marine pharmacy in our school pays great attention to the cultivation and training of students' practical ability, and has established a number of practical teaching platforms. According to the pharmacy profession's characteristics and teaching requirements, we have established 17 stable internship bases with well-known enterprises in the province, which can meet the internship requirements of students, and enable students to master the $R \& D$ and production process and precautions of common drugs, to get familiar with the principle, performance, use and maintenance requirements and configuration of commonly used drugs, and understand the operation mode of the drug quality control system and the application of new drug technology. We have indeed provided a good platform for students to improve their hands-on and practical skills. To further strengthen cooperation with emerging marine biomedical enterprises in the province, we need to establish and improve the various systems and cooperation methods of the practice base under the principle of mutual benefit. On this basis, an internship training base will be built into a practical teaching demonstration base to provide students with more and better internships and internship opportunities.

\section{A. Strengthening practical teaching}

Strengthen the construction of pharmacy comprehensive experimental center, reform the experimental teaching system, and strengthen the characteristic experimental teaching of marine biomedical emerging industry technology and pharmacy new technology application. We will further expand and strengthen the application and management of open experimental projects, increase the number of experimental class hours in pharmacy, increase the proportion of comprehensive and innovative experiments, and convert some mature research achievements into experimental teaching projects. Increase the experimental hours, so that the ratio of theoretical class hours to experimental class hours is close to 1:1 (excluding public basic courses, basic subjects, general education courses), and strengthen students' ability to practice, analyze and solve problems, and innovative ability. In order to ensure the effective and orderly implementation of the practical teaching, the construction of laboratories has been strengthened, and a practical teaching platform has been established. We have successively utilized the national central treasury and Zhejiang financial special projects to build a marine drug laboratory and a marine biomedical comprehensive laboratory.

\section{B. Internship and training base construction}

Based on the characteristics and teaching requirements of the pharmacy major, we have established a stable practice base with well-known enterprises in the province, so that students can master the R\&D and production process and precautions of common drugs, get familiar with the working principle, performance, use methods and maintenance requirements and configuration of commonly used drugs. At the same time, understand the operation mode of the drug quality control system and the application of new drug technology. It has been proved as a good platform for students to improve their handson ability and practical ability. We have built a Marine Biopharmaceutical Training Platform (marine medicinal resources research and development and new drug development, marine medicinal microbial metabolic engineering, genetic recombinase) and Separation and Purification Testing Laboratory for Marine Biometabolism by using construction projects such as marine biomedicine and marine biomedical products engineering center in Zhejiang Province. In addition, we have established 17 stable practice bases in cooperation with off-campus enterprises and institutions, further optimizing the training and internship conditions of marine pharmacy professionals.

\section{Emphasize the coordinated development of teaching- scientific research and encourage students to participate in scientific research activities as soon as possible}

While adhering to the core status of the teaching work, we must attach great importance to the role of scientific research in improving the quality of teaching, enhancing professional reputation, and strengthening the strength of running schools, and strive to improve the level of scientific research. At the same time, through the participation in scientific research activities, the cultivation of students' innovative ability is integrated into the whole process of scientific research in related disciplines. Starting from the "full-course tutor system", we will change the role of teachers from the "communicator, monopolist" of knowledge to the "growth tutor" of students [3]. At the beginning of the enrollment, students select instructors, and the instructor implements a four-year system to guide students to learn, conduct practical and scientific research activities to enhance students' innovative literacy, practical ability and potential development. We will pay more attention to the cultivation of students' innovative ability, start with "early participation in scientific research", combine students' theoretical knowledge learning with scientific research practice, and better cultivate innovative talents and their scientific literacy. As the sophomores, students have access to the professional laboratory; participate in the scientific research topics of pharmacy teachers. 3-4 students form a research group to ensure that students with the ability and interest enter 
the scientific research practice in the early stage, in order to enhance students' sense of innovation and innovation ability.

Through nearly ten years of unremitting efforts and arduous exploration, we have made remarkable progress in pharmacy professionals training and formed distinctive marine characteristics. In 2014, the pharmacy profession was approved as a specialty of Zhejiang Province, and our team was awarded as the excellent teaching team, and excellent research and innovation team of Zhejiang Ocean University. With the marine pharmacy profession, the traditional industry complements with the emerging disciplines, serving the local economic and social development. The school-enterprise integration development mechanism that meets the industrial needs is fundamentally established. The faculty is further optimized, forming biopharmacy, biology, pharmaceutical engineering, and pharmacy talent team. The specialty development has undergone a rapid development. The talent training model has been further optimized and the training capability has been gradually improved. A number of highquality applied professionals have been provided for the marine economy.

\section{CONCLUSION}

The marine pharmacy of marine biopharmaceutics is an emerging interdisciplinary subject, and there is a need for a model for the development of the discipline in the talent training. As a special specialty of Zhejiang Province, our university's marine pharmacy has put forward its own unique mode in the education of undergraduates, fully combining industrial development with talent training, and has successively carried out undergraduate and postgraduate education. Through our unremitting efforts and exploration in recent years, we have trained more than 1,000 talents in the marine biopharmeceutics strategy emerging industries to serve the Zhejiang marine economy and the Zhoushan Archipelago New Area.

\section{REFERENCES}

[1] Qu Youle. Research and Practice on the Training Mode of Applied Marine Pharmaceutical Talents. Pharmaceutical Education,2006,22(1):13.

[2] Huang Yi, Peng Zhou, Qu Youle, Guan Liping. On the Training Mode of High-Quality Applied Talents--Taking Marine Medicinal Chemistry as an Example.Management Observer, 2014(30):162-163.

[3] Wang Yan,Wenhong,Zhang Xuenong. On the Tutor System of Undergraduates in Pharmacy. Pharmaceutical Education,2011,27(4):1416.

[4] Yu Xuesong, Jia Weizhang, Hu Lili. Construction of Innovative Application Talent Training System for Marine Pharmacy. Basic Medical Education, 2017, 19(9): 660-662.

[5] Feng Zhihua, Xu Tianjun, Zhang Bingzhi. On the Cultivation of Scientific Research Quality of Undergraduates Major in Marine Science. Science and Technology Innovation Herald, 2010, 32: 169. 